the ethoxy group in the phenacetine. The bromine acting upon this portion of the molecule converts the compound into an intensely colored quinone derivative which makes it impossible to observe the end point of the reaction. Among the plans for getting around this difficulty which have so far been tried without success may be mentioned, the attempts to remove or render the ethoxy group inactive either by oxidation or reduction methods; titration with the use of spotting plates or test papers upon removed portions of the solution; and the use of mild saponifying agents for liberating aniline from the acetanilide without acting upon the phenacetine.

It was found that although acetanilide alone, and with less success phenacetine, could be titrated directly (without previous saponification) in the cold, acidified, aqueous solution with standard potassium bromate, the reaction is slow since time must be allowed for the dissolving of the phenacetine or acetanilide during the titration, and in addition the presence of caffeine serionsly interferes with the determination of the end point.

The only process which has appeared to be worthy of further study is based upon the statements found in Meyer and Jacobsen, vol. 2, p. 455, that chloride of lime acting upon $p$-aminophenols produces quinone chloramicle and this product is very easily reduced back to the $p$-phenol by means of reducing agents. Quantitative experiments made with stannous chloride as the reducing agent showed that if an excess of the bromate solution be added to the acid saponified solution of a mixture of acetanilide and phenacetine, this excess could be titrated back with stannous chloride and the difference corresponds fairly closely to the amount required by the acetanilide alone in the mixture. Further work will be required however to demonstrate the practical applicability of this procedure; and in the mean time it is hoped that the method as described for acetanilicle alone will prove useful particularly to the chemists having charge of the enforcement of the new Pure Food and Drug Law.

\title{
A STUDY OF THE INFLUENCE OF MAGNESIUM SULPHATE ON THE GROW'TH OF SEEDLINGS.
}

By Gertrude s. BURLINGHAM.

Received March 29, I907.

\section{Introduction}

This investigation is an outgrowth of a more comprehensive problem in nutrition, the aim of which was to learn the effects of the different minerai nutrients upon the growth of a test plant, from these data to compound a perfect nutrient solution, and then to note the variations in structure and form which might be produced by modifying the composition of this nutrient solution. Abutilon abutilon was chosen as the test plant, 
siace it had not been used in any similar experimentation and promised to yiald readily to water culture treatment. Early in the work, the response of one seedling to an m/rozt solution of magnesium sulphate attracted attention by the amount of its growth and the length of time which it lived. Accordingly, toxic and stimulation points having been established for various other mineral salts, special attention was giren to the effects of magnesium sulphate upon the growth of the abutilon seedlings. The results were so interesting that the investigation was carried farther. The data and conclusions which were established form the basis of this paper. The work is being continued along synthetic lines, and the results that nay be obtained in our study of the original nutrition problem will be presented in a future paper.

Nagnesium salts, in the absence of caicium, are generally considered to be inhibitory to plant growth. Dr. Loew" in his "Physiological role of mineral nutrients in plants," and again" in "Liming of soils from a physiological staudpoint', treats at some length the effects of magnesium salts on plants. As a result of his obserrations, he says "Plants succumb soon when placed in diluted solutions of magnesium salts and no other... in fact, magnesium salts can exercise their nutritive functions only in the presence of a sufficient amount of calciun salts... Only the lowest algae and fungi are exceptions". This is in unison with the findings of Wolff, Raumer, Kellerman, May, and others. On the other hand, Duggar observed that magnesium salts were not very toxic to the marine algae, and True and Gies, in their experiments on "The physiological action of some of the heavy metals in mixed solutions," found that the toxicity of magnesium chloride for lupin seedlings diminished greatly with dilution. They noted the fact that growth of the inpin root was practically equal in an m/2048 magnesium chloride solution to that in the water control, and also that decided stimulation of the growth of the root occurred in an $\mathrm{n} / 4096$ solution of magnesium chloride, as compared with that in the water control. It has also been demonstrated that a certain amount of magnesium is necessary for the perfect development of the higher plants, and spores will fot form in the lower fungi grown in solutions lacking magnesium. Furthermore bacteria, the lower fungi and the lower algae can thrive in the absence of calcium."

Among some of the most interesting investigations of the influence of magnesium compounds on animals, are the recent experiments of Meltzer and Auer. The results of their studies, from first to last, have led them to conclude "that magnesiun favors essentially or exclusively in-

'Loew : Bull. 45 Bur. Plant Ind. U. S. Dep't. Agri. (1903.)

"I oew : Bull, I Bur. Plant Ind. I. S. Dep't. Agri. (rgor).

"True and Gies : Bull. Torrey Bot. Cl. 30, 390-102 (1903). laborators: Biochemical Researches, 1, Reprint No. 37 (1903).

Also Gies and col-

t Loew: Bull. 45 Bur. Plant Int. C. S. Dep't. Agri. 1. 52. 
"ribitory processes in the animal body". The following quotation ${ }^{1}$ will give a good idea of their hypothesis. "At a certain phase of functional activity the inhibition of a reflex action, or of a sensation within a ganglion cell, is an indispensable factor in the prompt working of these functions, and these inhibitions require as much vital assistance for their development as is required and received by the positive energies of these tissues. The diastolic part in the cycle of a heart beat; the inhibition of the contraction of the inspiratory muscles in the cycle of a respiration ; the inhibition of a disturbing activity of any antagonistic muscle; the inhibition of a disturbing concomitant reflex; the inhibition of the activity of one sense during the act of perception of another sense,-in these and in many other instances the suppression, the inhibition of an activity is an indispensable part of a vital function. Is it not possible that the processes of inhibition are essentially facilitated by compounds which contain magnesium?"

Practically all the effects which Meltzer and Auer noted, were brought about by only relatively large doses, and they have not ascertained the effects of minute proportions. Therefore their results are in accord with those of botanists in indicating that magnesium is decidedly inhibitory in its biological effects, especially when present in quantities that are relatively large.

In this connection it may be well to mention the recent investigations of Loeb" upon "The rythmical contractions of a jelly fish." He drew the following conclusions as a result of his work: "I. The experiments show that the normal rythmical motions of a jelly fish (Polyorchis) will only occur in such solutions as contain magnesium and that the apparently spontaneous character of these rythmical motions depends upon the magnesium contained in sea water. 2. This effect of magnesium can be inhibited by the addition of an equivalent amount of calcium or potassium. 3. The isolated center of Polyorchis, which will not beat in a pure sugar solution or in sea-water, can be caused to beat in both solutions through the addition of a certain amoutst of calcium chloride, (or strontium chloride or barium chloride) but not by magnesium chloride. Magnesium inhibits the stimulating effect of calcium when magnesium is added in the ratio of at least four times the equivalent of calcium."

It is in consideration of the present interest in the physiological effects of magnesium and in view of the somewhat different theories advauced, that the results of these investigations upon the influence of magnesium sulphate on the growth of seedlings, are presented with the

1 Meltzer and Auer: Am. J. Plyysiol., 14, 367, 1905.

2Loeb. I. : J. Biol. Chem., 1, 427, I906. 
hope that they may throw some additional light upon the biological function of magnesium.

\section{Methods.}

The results were first established with the abutilon seedlings, representing a type of plant in which little food is stored in the seed, this supply being exhausted before the seedlings were transferred from the sphagnum to the culture solutions. Beakers of I 20 cc. capacity were used for the experiments, the seedlings being supported over the mouth of the beaker through holes in paraffined cork, and held in place by cotton plugs so that all roots were immersed in the solution to the same depth. Three seedlings were grown in each culture in any series, and their growth taken at intervals not greater than 48 hours, (for the first 168 hours), the solutions being renewed at the end of 96 hours. For the purpose of measurement the seedlings were removed from the solution and laid upon a chemically clean glass slide which was placed over a flat metric scale. In this way contamination was made impossible. The magnesium solutions were prepared with distilled water and Kahlbaum " $K$ " salts. The results obtained in the first series are indicated in table $\mathrm{I}$.

\section{TABIE I}

Series I with abutilon seedlings and magnesium sulphate. Experiment was started Feb. Io, Igo6. Average growth given in millimeters.

H. = hypocotyl. R. = root. Pl. =: plunule.

\begin{tabular}{|c|c|c|c|c|}
\hline Culture & $\begin{array}{l}\text { Sec. Rts. } \\
\text { appeared }\end{array}$ & $\begin{array}{l}\text { Growth } \\
\text { in I68 Hours }\end{array}$ & $\begin{array}{l}\text { Rematks } \\
\text { on growth }\end{array}$ & $\begin{array}{l}\text { Death and } \\
\text { symptoms }\end{array}$ \\
\hline Water & 4th day & 29. I $\left\{\begin{array}{l}\text { H.23. I } \\
\text { R. } 6 .\end{array}\right.$ & Pl. started Fely. I7 & Tops died Feb. 23 \\
\hline $\begin{array}{l}\mathrm{MgSO} \\
\mathrm{m} \cdot 12 \mathrm{~S}\end{array}$ & $\cdots \cdots$ & $19.3\left\{\begin{array}{l}\mathrm{H} .19 .3 \\
\mathrm{R} .\end{array}\right.$ & P1. dia not revelop & Rts. flaccid Feb. 17 \\
\hline $\ln : 256$ & $\cdots \cdots$ & I $8.2\left\{\begin{array}{l}\text { H. I } 7.6 \\
\text { R. } .6\end{array}\right.$ & P1. did not develop & Rts. flaccid Feb. I7 \\
\hline$m 512$ & $\ldots \ldots$ & 28. $\left\{\begin{array}{l}\text { H.26 } \\
\text { R. } 2\end{array}\right.$ & Pl, did not develop & Rts. flaccid Feb. I 7 \\
\hline$m_{1}: 024$ & $\cdots \cdots$ & 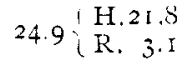 & P1. started Feb. 17 & Rts. flaccid Feb. I7 \\
\hline$m ; 2048$ & 4th day & I $8.3\left\{\begin{array}{l}\text { H. I5. I } \\
\text { R. } 3.2\end{array}\right.$ & One died Feb. I7 & Rts. flaccid Feb. 23 \\
\hline$m_{i}+096$ & $\ldots \ldots$ & $2 \mathrm{I} .3\left\{\begin{array}{l}\text { H.18.5 } \\
\text { R. } 2.8\end{array}\right.$ & & Rts. flaccid Mar, 2 \\
\hline$m 819^{2}$ & 4th day & $30.6\left\{\begin{array}{l}\text { H. } 17.7 \\
\text { R.I } 2.3\end{array}\right.$ & Healthy Feb. I7 & Tops died Mar. 2 \\
\hline$m_{1}, 1638_{4}$ & 4th day & $49.6\left\{\begin{array}{l}H .30 .8 \\
R .18 .8\end{array}\right.$ & P1. started Feb. I6 & Tops died Feb. 24 \\
\hline
\end{tabular}

\section{Results.}

The action of $m / 128$ and $m_{1}^{\prime} 256$ magnesium sulphate solutions mas so plainly toxic that they were eliminated in subsequent trials. Although the total growth in $m / 8192$ was less than in the control, the root growth was the same in both; while the ratio between the average total growth 
in the coutrol and in $m / 16384$ was $29: 49$, and the relation between the root growths was $6: 18$. In the next series the dilution was carried two points farther. The details of this experiment are given in table 2.

\section{TABLE 2}

Series 2 with abutilon seedlings and magnesium sulphate. Experiment was started Feb. 26, 1906. Average growth given in millimeters.

$\mathrm{H} .=$ hypocotyl $\quad \mathrm{R} .=$ root $. \mathrm{Pl} .=$ plumule

\begin{tabular}{|c|c|c|c|c|}
\hline Culture & $\begin{array}{l}\text { Sec. Rts, } \\
\text { appeared }\end{array}$ & $\begin{array}{c}\text { Growth } \\
\text { in } 168 \text { hours }\end{array}$ & $\begin{array}{l}\text { Remarks } \\
\text { on growth }\end{array}$ & $\begin{array}{l}\text { Death and } \\
\text { symptoms }\end{array}$ \\
\hline $\begin{array}{l}\text { Water } \\
\mathrm{MgSO}_{4}\end{array}$ & $4^{\text {th }}$ day & $37.2\left\{\begin{array}{l}\text { H. } 27.6 \\
\text { R. } 9.6\end{array}\right.$ & P1. started Mar. I3 & Tops died 8th day \\
\hline$m / 512$ & $\cdots \cdots$ & I $8.4\left\{\begin{array}{l}\text { H. I } 7.6 \\
\text { R. } .8\end{array}\right.$ & Pl. did not develop & Roots flaccid 3 rd day \\
\hline$m_{1} 1024$ & $\cdots \cdots$ & I9.3 $\left\{\begin{array}{l}\text { H. } 18.5 \\
\text { R. } .75\end{array}\right.$ & P1. did not develop & Roots flaccid ${ }_{3}$ rd day \\
\hline$m / 2048$ & $4^{\text {th }}$ day & 25. I $\left\{\begin{array}{l}\text { H. } 22.3 \\
\text { R. } 2.8\end{array}\right.$ & P1. did not develop & Roots flaccid Sth day \\
\hline$m / 4096$ & $\cdots \cdots$ & $27.3\left\{\begin{array}{l}\text { H.24. } \\
\text { R. } 3 \cdot 3\end{array}\right.$ & Alive Mar. 7 & \\
\hline$m_{;} 8192$ & $4^{\text {th }}$ day & 6 r. $6\left\{\begin{array}{l}\mathrm{H} .33 \cdot 3 \\
\mathrm{R} .28 .3\end{array}\right.$ & Pl. started Mar. 5 & Tops died 8th day \\
\hline$m / 16384$ & $4^{\text {th }}$ day & $52 . \mathrm{I}\left\{\begin{array}{l}\text { H. } 38.5 \\
\text { R.I } 3.6\end{array}\right.$ & & Cotyls dying Sth day \\
\hline$m / 32768$ & 4th day & 5 I.6 $\left\{\begin{array}{l}\text { H. } 34 \cdot 3 \\
\text { R.I } 7.3\end{array}\right.$ & Pl. started Mar. 3 & See notel \\
\hline$m / 65536$ & $4^{\text {th }}$ day & $7 \mathrm{r} .3\left\{\begin{array}{l}\mathrm{H} .35 . \\
\mathrm{R} .36 .3\end{array}\right.$ & P1. started Mar. 7 & Cotyls dying Mar. I 3 \\
\hline
\end{tabular}

As a result of the observations recorded in tables $I$ and 2 , it is evident that magnesium sulphate in concentrations greater than $m / 8192$ is toxic to seedlings of abutilon, as is shown by the inhibition of growth and the flaccidity of the roots after a few days. While in dilutions greater than this, there are indications of a beneficial action. Accordingly, in the remaining series with abutilon seedlings, $m / 8193$ was taken as the starting point.

\section{TABLE 3}

Series 3 with abutilon seedlings and magnesium sulphate. Experiment was started Mar. 4, 1906. Average growth for first 168 hours given in millimeters.

$$
\text { H. = hypocotyl. } \quad \text { R. }=\text { root. }
$$

\begin{tabular}{|c|c|}
\hline Culture & Growth in 168 hou \\
\hline $\begin{array}{l}\text { Water } \\
\mathrm{gSO}_{4}\end{array}$ & $32.5\left\{\begin{array}{l}\text { JI. } 28 \\
\text { R. } 4.5\end{array}\right.$ \\
\hline$m 8192$ & $43.2\left\{\begin{array}{l}\text { H. } 27.6 \\
\text { R.I } 5.6\end{array}\right.$ \\
\hline$m_{1} 6_{3} 84$ & $53.6\left\{\begin{array}{l}\text { H. } 32 . I \\
\text { R.2I.5 }\end{array}\right.$ \\
\hline$m_{32768}$ & $44.9\left\{\begin{array}{l}\text { H. } 28.6 \\
\text { R.I6.3 }\end{array}\right.$ \\
\hline$m / 65536$ & 46. $\left\{\begin{array}{l}\text { H.30. } \\
\text { R.16. }\end{array}\right.$ \\
\hline
\end{tabular}

Rematks on growth

Secondary roots numerous in

all. Longest in $m / 65536$. Plumule started first in $m / 16384$.

Condition in all normal, March

I I

1 Number I died on the I $4^{\text {th }}$ day, number 2 lived until June I, and developed several sets of leaves. The death of number 3 was not recorded but it outlived number $\mathrm{I}$. 
Series 1 .
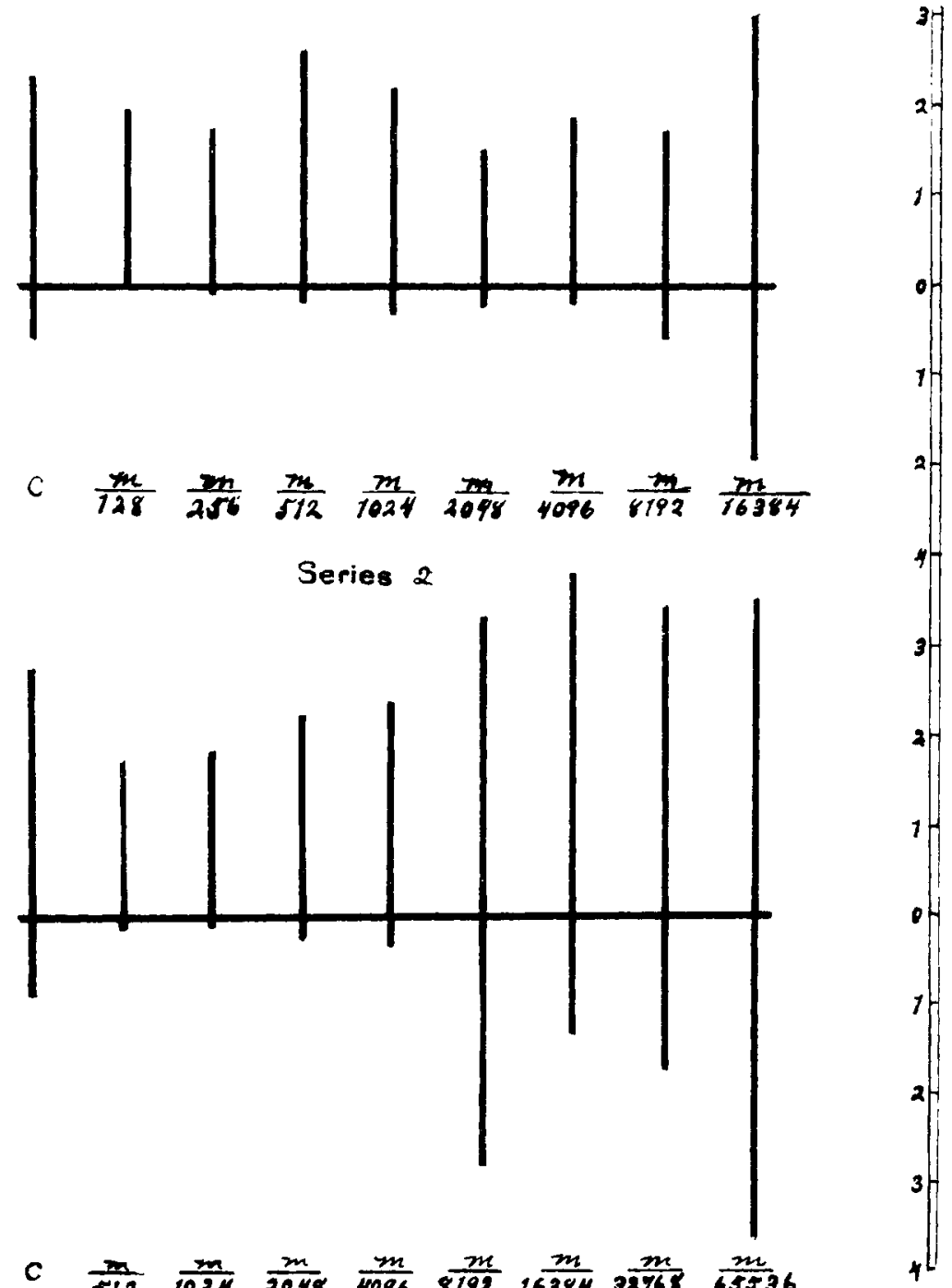

\section{c $\frac{m}{512} \frac{m}{1024} \frac{m}{2048} \frac{m}{4096} \frac{m}{8192}, \frac{m}{16384} \frac{m}{32768} \frac{m}{65936}$ PLATE I}

Diagrans showing the actual growth of the abutilon seedings in the control $(C)$ and in the different concentrations of $\mathrm{MgSO}_{4}$ in series I and 2.

The marginal units are in centimeters. The root growth is sbown below the base line, the growth of hypocotyl, above.

At this point it seemed best to compare the growth of abutilon seedlings in these favorable dilutions of magnesium sulphate with the growtb 
in similar dilutions of a calcium salt. Two parallel series were started, each consisting of seven cultures; the one magnesium sulphate and control, the other calcium uitrate and control. Table 4 gives a summary

\section{TABLE 4}

Series 4 with abutilon seedlings and magnesium sulphate, and abutilon seedlings with similar solutions of calcium nitrate. Experiment was started March I2, Igo6.

Average growth for 120 hours given in millimeters.

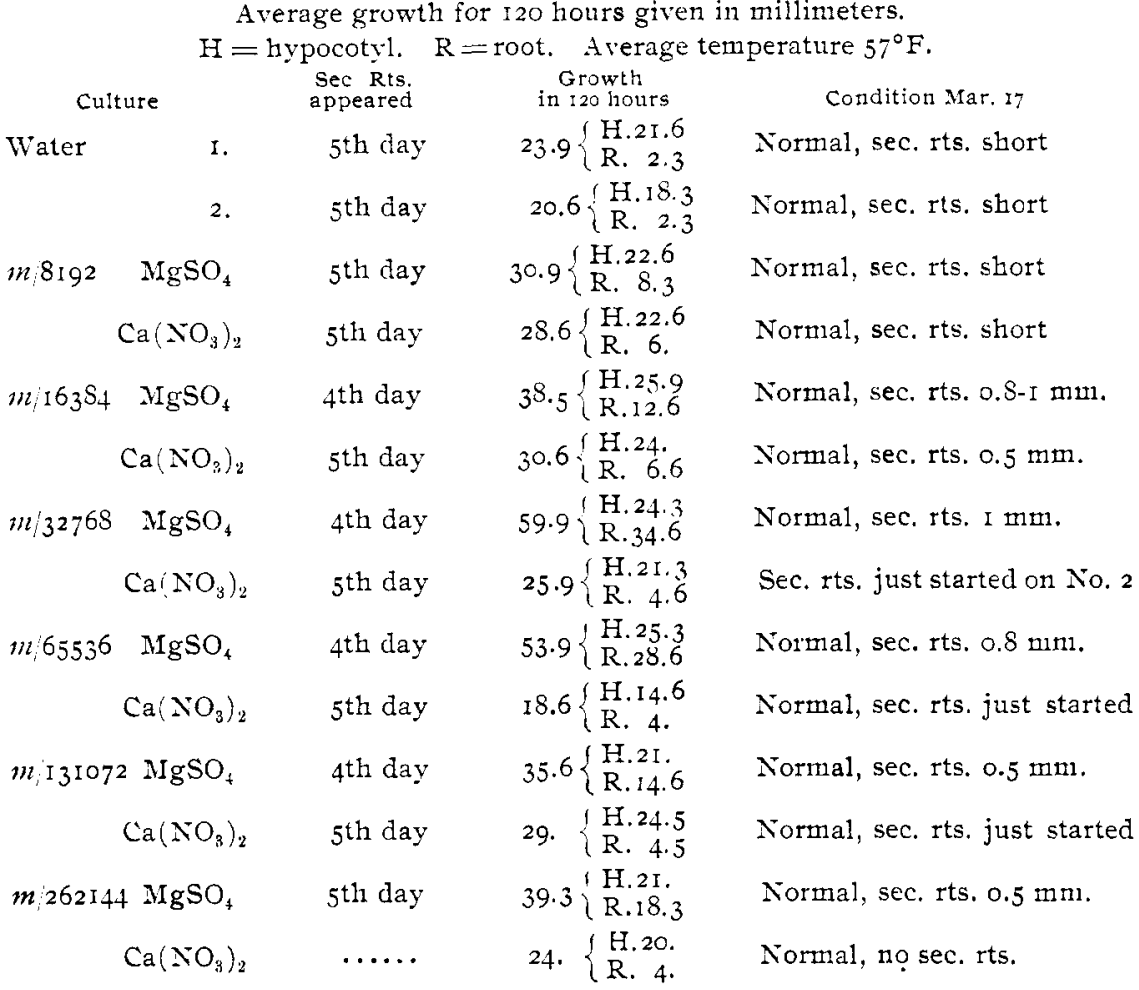

of the results. It is seen that throughout the series, the growth of seedlings is greater in the magnesium sulphate solution than in the corresponding dilution of calcium nitrate. This is not because of the toxicity of the calcium nitrate, the toxic point having already been established at concentrations above $m / \mathrm{ro24}_{\text {; }}$ and besides, the seedlings were as healthy as those in water. It is evident that calcium ceases to be stimulating in the dilutions at which magnesium no longer exhibits toxicity but reaches its greatest stimulative power. The stimulating effect of the magnesium sulphate was most noticeable in the root growth; in $\mathrm{m} / 32768$ being fifteen times that in the control, and eight times that in the calcium uitrat $\epsilon$ culture of the same dilution. The secondary roots appeared sooner in the magnesium sulphate cultures and reached a greater growth. Hence it again becomes evident that in certain concentrations, both calcium salts 
and magnesium salts are toxic. It is also certain that in the case of both maguesium and calcium, there is a dilution at which the toxic action ceases and stimulation begins. For abutilon seedlings in the case of nuagnesium this point seems to be at a concentration approximately equal to that of an $m / 8192$ solution of magnesium sulphate.

In order to be sure beyond doubt that the stimulating effects noted in the preceding experiments were not due to any impurity in the salt used, a new Kahlbaum product was carefully analyzed and another stock solution made from this tested salt. Another series was grown in cultures prepared from this solution, and the results were in accordance with those obtained in previous trials. A summary of these results is given in table 5 .

I'ABLE 5

Series 5 with abutilon seedlings and magnesium sulphate. Experiments were started October 27, Igo6. Average growth given in millimeters.

\begin{tabular}{|c|c|c|c|}
\hline Culture & $\begin{array}{l}\text { Sec. Rts. } \\
\text { appeared }\end{array}$ & $\begin{array}{l}\text { Growth } \\
\text { in iss hours }\end{array}$ & Condition on Nov. 7 \\
\hline $\begin{array}{l}\text { Water } \\
\text { IgSO }\end{array}$ & 5th day & $32.9: \begin{array}{l}\mathrm{H} .31 .6 \\
\mathrm{R} . \mathrm{I} \cdot 3\end{array}$ & Roots dead and flaccid \\
\hline$m$. 8192 & $\cdots \cdots$ & $32.3\left\{\begin{array}{l}\text { H.29. } \\
\text { R. } 3.3\end{array}\right.$ & P1. just started \\
\hline$m \cdot 163 S_{4}$ & 3 rd day & $45.3\left\{\begin{array}{l}\text { H. } 37.66 \\
\text { R. } 7.6\end{array}\right.$ & $\begin{array}{l}\text { P1. started in all, partly dried cotyls } \\
\text { in } 2 \text { and } 3 \text {, good sec. roots }\end{array}$ \\
\hline$m 32768$ & 3 rd day & $49.3\left\{\begin{array}{l}\mathrm{H} \cdot 40.3 \\
\mathrm{R} .9 .\end{array}\right.$ & $\begin{array}{l}\text { All healthy, color good, pl. started } \\
\text { strong sec. roots }\end{array}$ \\
\hline mi 65536 & $\begin{array}{l}\text { 2nd } \& \\
\text { 3rd day }\end{array}$ & 4 I. $2\left\{\begin{array}{l}\mathrm{H} .35 .6 \\
\text { R. } 5.6\end{array}\right.$ & $\begin{array}{l}\text { Cotylis dried on No. 2, others healthy, } \\
\text { color not so gooil as in last, pl. just started }\end{array}$ \\
\hline$m \cdot 131072$ & 3 rd day & $56.6: \begin{array}{l}\text { H. } 38.3 \\
\text { R.I } 8.3\end{array}$ & $\begin{array}{l}\text { All healthy, pl. started, good sec. } \\
\text { roots }\end{array}$ \\
\hline$m 262$ I +4 & $\begin{array}{l}\text { 2nd } \mathbb{S} \\
\text { 3rd day }\end{array}$ & $43 \cdot 3: \begin{array}{l}\mathrm{H} \cdot 36 \cdot 3 \\
\mathrm{R} \cdot 7\end{array}$ & All healthy, pl. started, good sec. \\
\hline$m \longdiv { 5 2 4 2 8 5 }$ & 3 rol day & $43.6\left\{\begin{array}{l}\mathrm{H} .36 \\
\mathrm{R} .7 .6\end{array}\right.$ & $\begin{array}{l}\text { No. I and } 2 \text { healthy except a black spot on } \\
\text { one cotyl. Pl. smaller than in preceding }\end{array}$ \\
\hline
\end{tabular}

As in former experiments the growth was stimulated by the magnesium sulphate, with the exception of the $m / 8$ i 92 solution. The growth in this instance was $0.7 \mathrm{~mm}$. less than in water, and secondary roots did not appear; and at the end of three weeks, the roots were flaccid. Since the growth in all three seedlings was vigorous and uniform, the results were evidently due to the action of the magnesium. In series 2 , the $m / 8192$ solution produced a stimulation of $24.3 \mathrm{~mm}$.; while in series $I, 3$, and 4 , the stimulation varied from $0.9 \mathrm{~mm}$. to $10.7 \mathrm{~mm}$. This fluctuation in result is not unusual for a molecular solution which, in its strength, is on the border between such as are toxic and such as stimulate. And it is also probable that the point of toxicity varies to a certain extent with the temperature. ${ }^{1}$ The maximum stimulation in this

${ }^{1}$ According to Brooks in "Temperature and Toxic Action" (Botan. Gaz., 42: 359, (I 906 ) as related to spore germination, toxicity increases with the rise of temperature. Since these experiments with magnesium sulphate were not carried on at constant temperatures, no such definite conclusions can be drawn. But it is a point well worth considering. 
Series 4
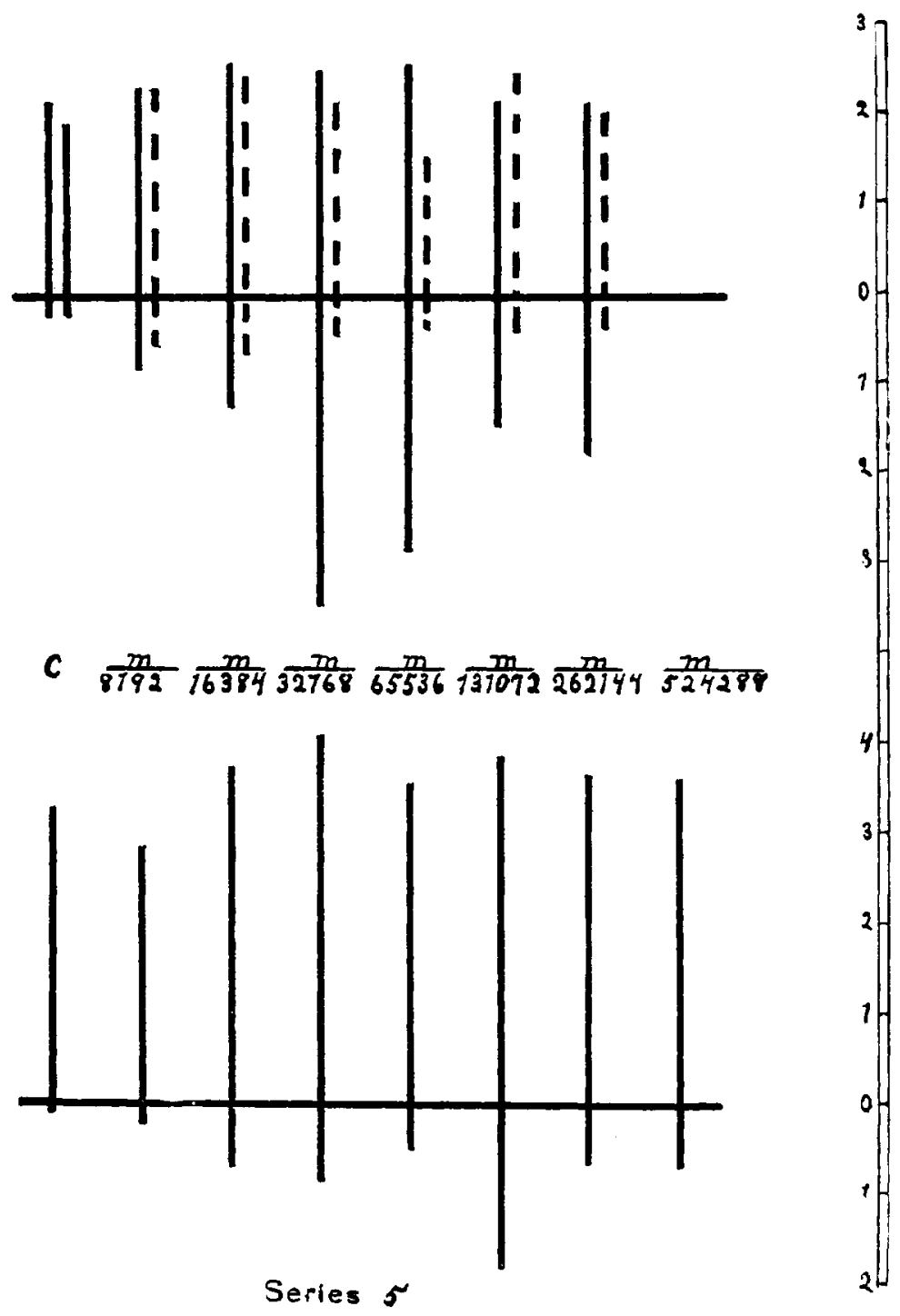

Series 5

c $\frac{m}{8192} \frac{m}{16384} \frac{m}{32768} \frac{m}{65536} \frac{m}{137072} \frac{m}{262144} \frac{m}{524287}$

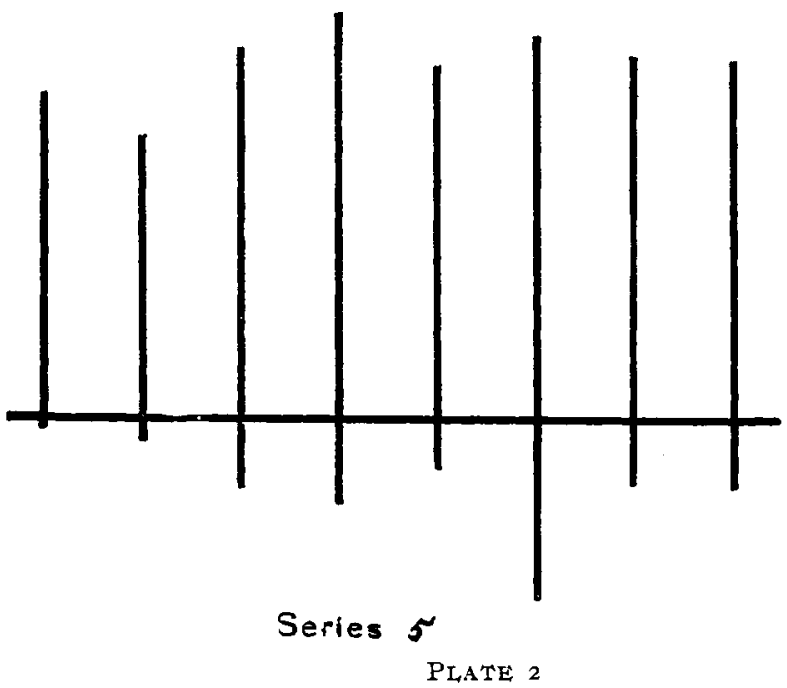

Series 4: Diagram showing the comparison between the actual average growth during 120 hours, of abutilon seedlings in various concentrations of $\mathrm{MgSO}_{4}$ and in similar concentrations of $\left(\mathrm{CaNO}_{3}\right)_{2}$ with controls $(C)$. The growth in $\left(\mathrm{CaNO}_{3}\right)_{2}$ is indicated by broken lines.

Series 5: Diagram of growth illustrating table 5.

The root growth is shown below base line, the growth of hypocotyl above. The marginal units are in centineters. The molecular fractions apply to both series. 
series occurred in m/131072. In dilutions beyond m/8192, secondary roots appeared from two to three days sooner than in the control. The plumule developed to a greater extent and the color was better. As in former cases, death in the magnesium sulphate cultures began in the cotyledons, while the roots remained vigorous for weeks. These results verified the previous conclusion that in proper dilutions magnesium salts have a stimulating effect on the growth of abutilon seedling's.

The Abutilon is a type of dicotyledonous plants having seeds with leafy cotyledons and little endosperm. As has been previously stated, the seedlings were transferred to the culture as soon as the seed-coat was shed, having at that time used the stored nourishment of the seed, so that a reserve food supply was eliminated as a factor. In orcler to determine whether the response to the presence of magnesium was due to peculiarities of this particular plant or to the type of seedling, experinentation was begun with seedlings of pea and corn. These seeds were washed and soaked in clistilled water for twenty-four hours, then germinated in spliagnum. When the roots were from two to four centimeters in length, the seedlings were transferred to the cultures. Throughout a series, however, seedlings having uniform grow th were selected as far as possible. These were suspended from the bent points of glass rods supported over the months of beakers by sheet cork. Beakers of uniform size were used, each containing $300 \mathrm{cc}$. of a given solution, this being renewed as in previous experiments at the end of 96 hours. The results of the first series with pea seedlings are shown in tablc 6 .

\section{TABLE 6}

Series 6, with pea seedlings and magnesiun sulplate. Experinent was started Oct. 26, 1906. Average root growth in millimeters.

\begin{tabular}{|c|c|c|c|}
\hline Culture & $\begin{array}{l}\text { Sec. Rts. } \\
\text { appeared }\end{array}$ & $\begin{array}{l}\text { Growth } \\
\text { in } 168 \text { hours }\end{array}$ & Condition on Nov. 7 \\
\hline $\begin{array}{l}\text { Water } \\
\mathrm{MgSO}_{4}\end{array}$ & $3 r d$ day & 37.33 & $\begin{array}{l}\text { Growth nearly stopped, sec. rts. up to } \mathrm{I} g \mathrm{~mm} \text {. } \\
\text { long }\end{array}$ \\
\hline$m 8192$ & $3 \mathrm{rd}$ day & 24.66 & $\begin{array}{l}\text { Root growtil stunted, gr. ceased, sec. rts. few, } \\
\text { up to } 14 \mathrm{~mm} \text {. long }\end{array}$ \\
\hline$m: 6_{3} s_{4}$ & $3+1$ day & 66.33 & Growth very active, sec. rts. up to $33 \mathrm{~mm}$. long \\
\hline$m 32768$ & $3 \mathrm{rat}$ तay & 71.33 & Growth very active, sec. rts. up to $28 \mathrm{~mm}$. long \\
\hline$m 65536$ & $3 \mathrm{rd} \mathrm{day}$ & $59 \cdot 33$ & Growth active, sec. rts. up to $20 \mathrm{~mm}$. long \\
\hline$m 1310 \% 2$ & 3 rd day & 63.33 & Growth active, sec. Its, wp to IS $\mathrm{mm}$. long \\
\hline$m: 262144$ & $4^{\text {th }}$ day & 62. & Growtl áctive \\
\hline$m 52+288$ & $3 r d$ day & 52.66 & Growtl active, sec. rts. up to $8 \mathrm{~mm}$. long \\
\hline
\end{tabular}

This experiment was twice repeated, extending the dilution one point farther each time, in order to ascertain at what dilution the stimulating effect would fail to occur. The $m / 8$ I 92 solution was universally toxic to the pea seedlings, stunting the growth of the primary root, and preventing the normal development of lateral roots. In fact, there was very little lengthening of the primary root after 96 hours. In series 6 and 8 however, at the end of two weeks, the lateral roots had attained a growth 


\section{Series 6.}
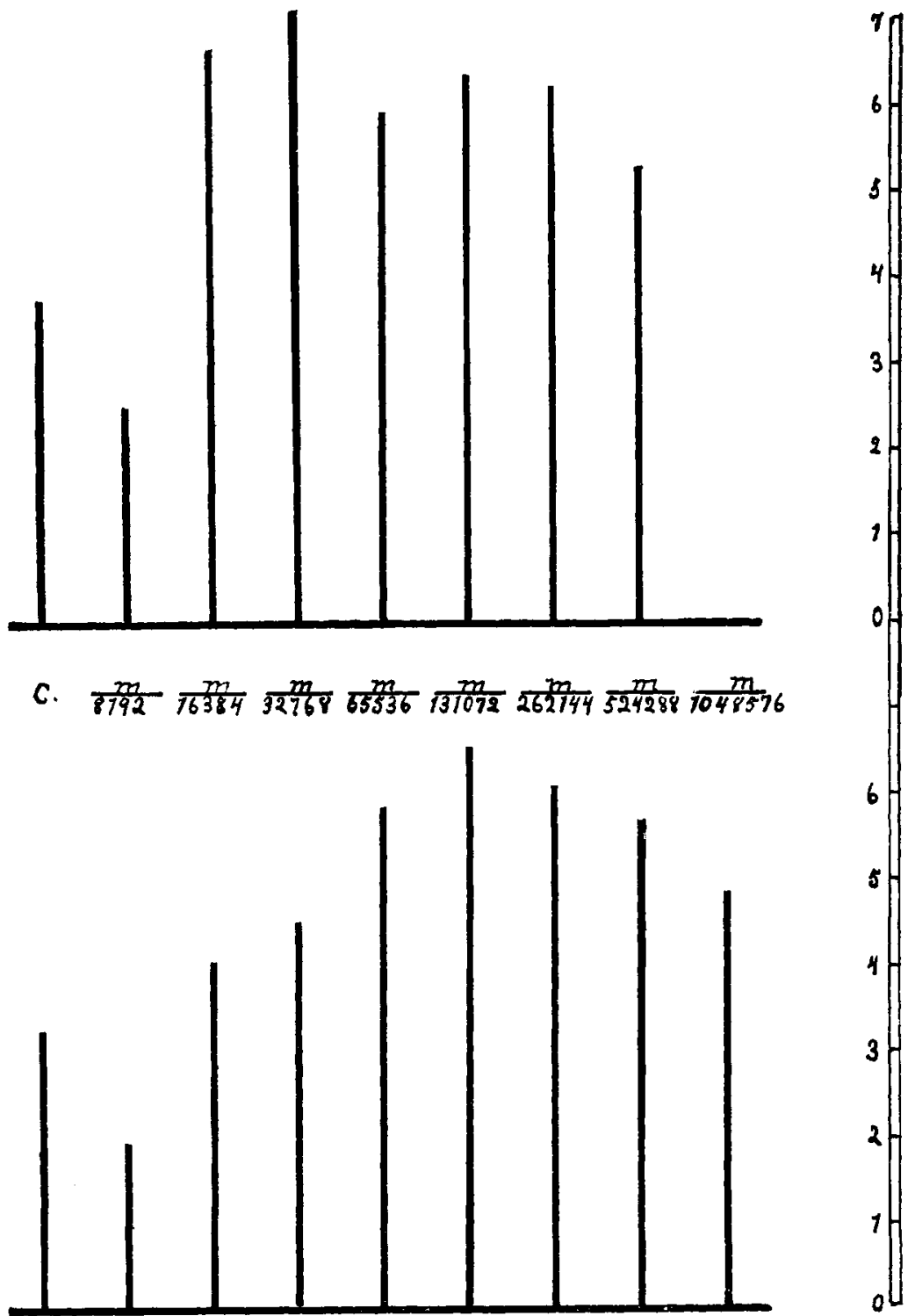

C. $\frac{m}{8792} \frac{m}{16384} \frac{m}{32768} \frac{m}{65336} \frac{m}{131072} \frac{m}{262144} \frac{m}{524288} \frac{m}{1048576}$

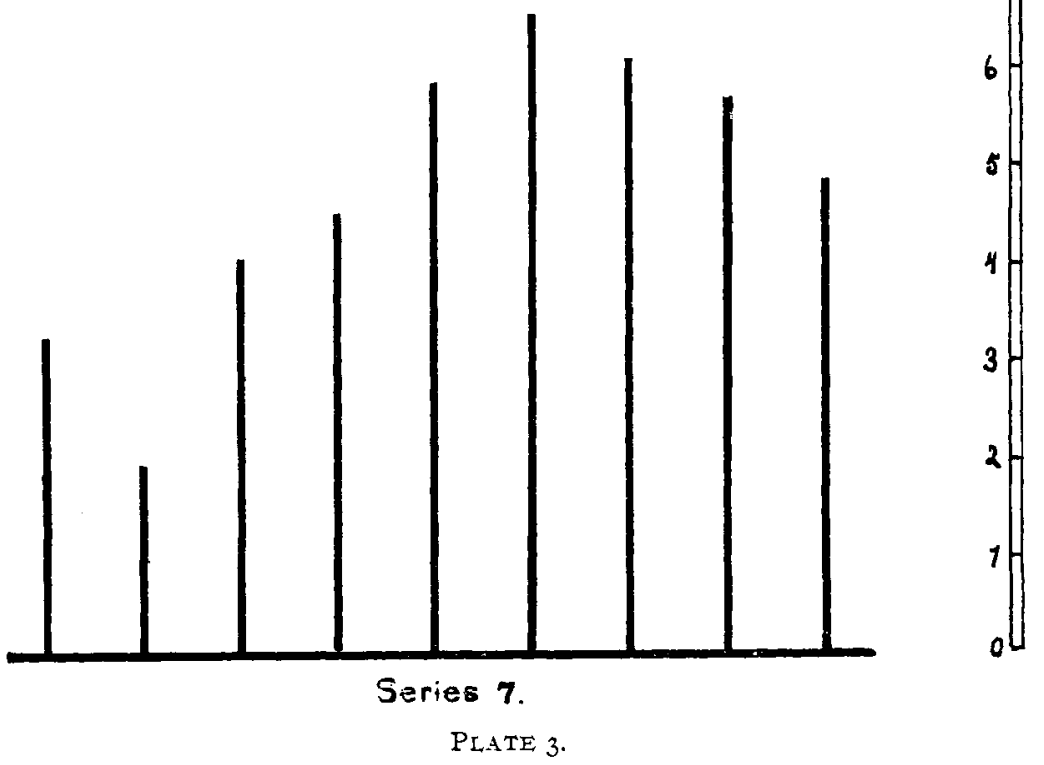

Diagrams showing the actual average root growth during 168 hours of the pea seedlings in the control $(C)$ and the different concentrations of $\mathrm{MgSO}_{4}$, Series 6 and 7 . The marginal units are in centimeters. The molecular fractions apply to both series. 
greater than in any of the other seedlings. This may have been due to the added stimulation produced by the inhibition of the primary root, or it is possible that the cells of the root may have become acclimated to the magnesium sulphate so that the action was no longer toxic.

While $m / 8192$ was toxic, decided stimulation was shown in $m / 16384$, becoming greater in concentrations up to $m / 13072$, then falling off uutil in $m / 2097152$, growth was little more than that in the control. Even here however, there was perceptible stimulation. The lateral roots developed best in m/262I44, forming in the course of five or six weeks, a branched system. In series 7 the root tips in the control were flaccid at the end of one week, and, in every instance, very little growth took place in the control seedlings after 168 hours; while growth in the magnesium sulphate cultures continued for four or five weeks longer. Table 7 gives a summary of the growth results in the three series.

\section{TABI.E 7}

Comparing the results obtained in series 6,7 and 8 , with pea seedlings and mangnesium sulphate. The growth for 168 hours is indicated in millimeters.

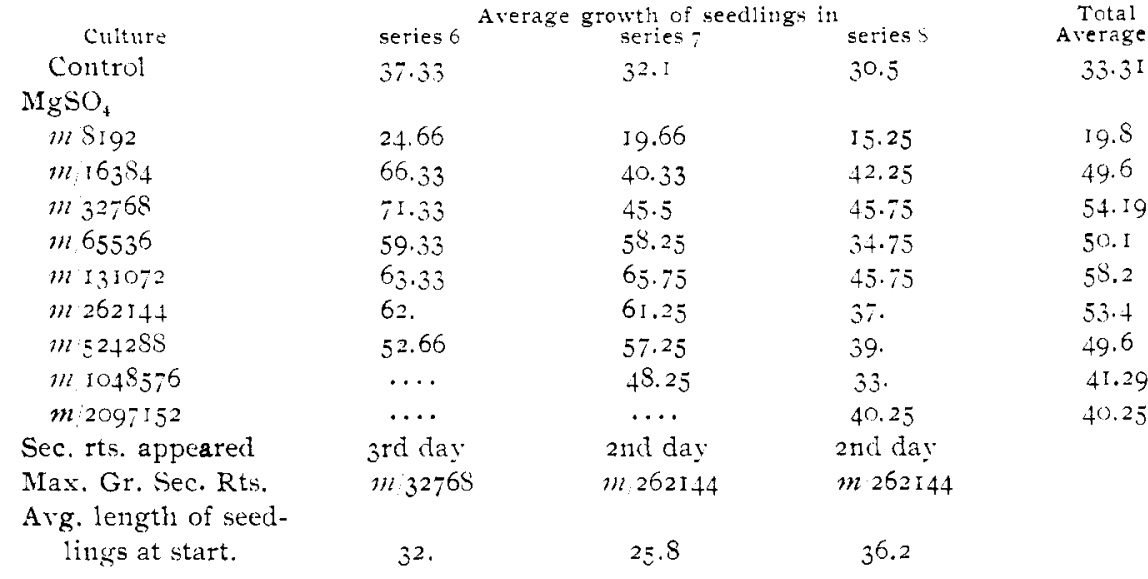

In the experiments with corn the same methods were followed as with the pea seedlings. In both series with corn, the greatest growth was in the $m / 32768$ magnesium sulphate solution, in series 9 being double that in the control, while the $m / 8 \mathrm{I}_{92}$ solution produced a vigorous growth, and the root tips were very active, as shown by the secretion at the tip. In dilutions greater than $m / 524288$ there was no stimulation. In series IO, $m /$ ro24 was taken as the greatest concentration. Even in this, the toxic action, with one exception, was indicated only in the abnormal secretion at the root tips. This secretion was noticeable at the end of 24 hours, appearing as a large glutinous drop on the end of the root, when the seedling was lifted from the solution. The secretion diminished 
in solutions of less concentration, being absent in dilutions greater than $m / 8192$. The results of both series are given in table 8 . (page II08).

\section{Series 8}

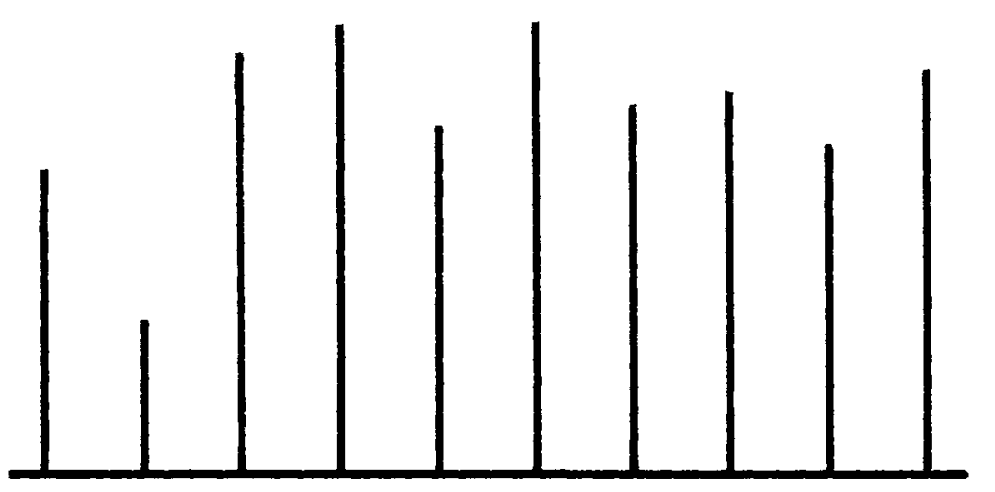

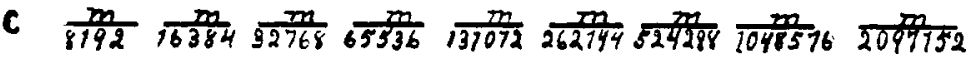

Fig. B.

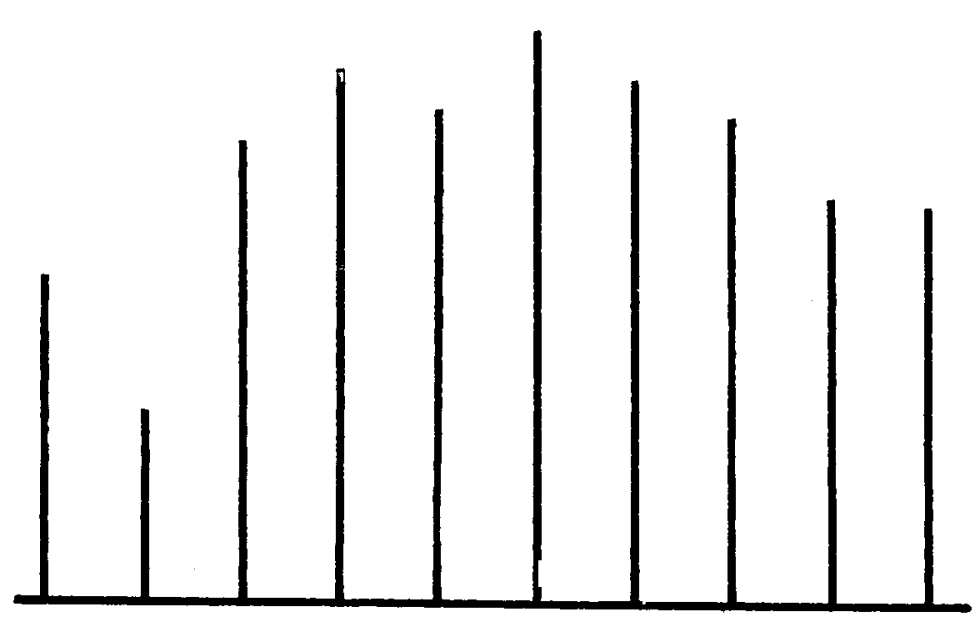

PIATE 4

Series 8: Diagram showing the actual average growth during 168 hours, of pea seedlings in the control $(C)$ and in the different concentrations of $\mathrm{MgSO}_{4}$. Fig. b.: Diagram showing the actual average root growth of the pea seedlings in series 6,7 , and 8 .

The marginal units are in centimeters. The molecular fractions apply to both series. 
TABLE 8

A comparison of the growth in series $g$ and so with corn seedlings and magnesium sulphate. Series 9 started Nov, r2, series io started Nor, 28 . Average growth of seedlings for 168 hours given in millimeters. 3 seedlings grown in each of series $9,+$ seedlings in series $\mathrm{ro}$.

\begin{tabular}{|c|c|c|c|}
\hline Cuiture & $\begin{array}{l}\text { Growth } \\
\text { Seties } 9\end{array}$ & $\begin{array}{l}168 \text { hours } \\
\text { Series :ol }\end{array}$ & Remarks on growth \\
\hline Water & 70 & 83.75 & \\
\hline \multicolumn{4}{|l|}{$\mathrm{IgSO}_{4}$} \\
\hline$m 1024$ & & 87 & Abnomal secretion at tip \\
\hline$m 20.19$ & & 95 & Abnormal secretion at tip \\
\hline$m 4096$ & & 75.5 & Secretion less than above \\
\hline$m 8192$ & I 33 & 96.25 & Roottip very active \\
\hline n. 16384 & 135.3 & 97.25 & Root hairs on this and $m, S 192$ \\
\hline$m 32768$ & I 46.5 & I 25.5 & Maximum stimulation \\
\hline$m 55536$ & I 14.5 & 95.75 & \\
\hline$m 131072$ & 120.3 & 75.5 & \\
\hline$m 262541$ & 102 & 89.75 & \\
\hline 111524288 & 59.3 & $s_{4}$ & Two roots curled in series 9 \\
\hline$m 104 \$_{576}$ & 57 & & One root curlect \\
\hline$m 2057152$ & 69 & & Normal, no stimulation \\
\hline Avg. Temp. & $65^{\circ} \mathrm{F}$ & $61.9^{\circ} \mathrm{F}$ & \\
\hline Range & $45^{\circ}-75^{\circ} \mathrm{F}$ & $49^{\circ}-73^{\circ} \mathrm{F}$ & I,ateral roots appear 6 th day \\
\hline
\end{tabular}

Comparison of the daily growth rate throughout series I-IO, shows the growth rapid for the first 48 hours, then diminishing in rate for the next 48 , and after the renewal of the solutions, increasing in the magnesium sulphate cultures above $m / 8192$, while the growth rate in the control seedlings either remained the same or diminished. (See table 9).

\section{TABLE 9}

Showing the comparative daily growths in series 9 with corn seedlings and magnesiun sulphate. The growths in each case represents the average of the three seedlings. Measurements in millimeters.

\begin{tabular}{|c|c|c|c|c|c|c|}
\hline Culture & $\begin{array}{c}\begin{array}{c}1 \text { st } \\
24 \mathrm{hrs} .\end{array}\end{array}$ & $\begin{array}{c}2 \mathrm{nd} \\
24 \mathrm{hrs}\end{array}$ & $\begin{array}{c}34^{3 \mathrm{rd}} \\
\mathrm{hrs}\end{array}$ & $\begin{array}{c}4 \text { th } \\
24 \text { hirs. }\end{array}$ & $\begin{array}{c}\text { sthin } \\
2+\text { hrs. }\end{array}$ & $\begin{array}{c}6 \text { th s ith } \\
2+\text { his. }\end{array}$ \\
\hline Water & II. 5 & 13.8 & I 6.5 & 6.66 & 6.16 & 13.66 \\
\hline \multicolumn{7}{|l|}{$\mathrm{IgSO}_{4}$} \\
\hline $17 \cdot 8192$ & 12. & I 5.33 & 21.66 & 15. & I 5.66 & $53 \cdot 3$ \\
\hline$m I \sigma_{3} \delta_{4}$ & II. 3 & 16.66 & Is. & 22.3 & 17.66 & 49.3 \\
\hline$m 32769$ & II & 13.6 & $2 \mathrm{I} .5$ & IS. & 19.5 & $5^{8}$ \\
\hline$m 65536$ & Io. & I6. & 19.66 & I 3.3 & II. 3 & $43 \cdot 3$ \\
\hline$m I_{3} \mathrm{IO}_{72}$ & 14.3 & 21.3 & 23.6 & 14.3 & I 5. & 31.75 \\
\hline$m 262 \mathrm{I}+4$ & I 2.6 & 22.6 & $25 \cdot 3$ & if. & 6.6 & 20. \\
\hline
\end{tabular}

In the roth series with corn seedlings, the solutions were not changed at the end of 96 hours, with the result that the growth rate in the magnesium cultures was below that in the control at the end of 168 hours. On the ninth day, however, the solutions were renewed for $m / 8192$, $m_{3} 32768$ and the control. Measurements were taken for 72 hours; the

I The solutions were not changed at the end of 96 hours in series 10 , and the growth during the last 72 hours was much less than in series 9 . 


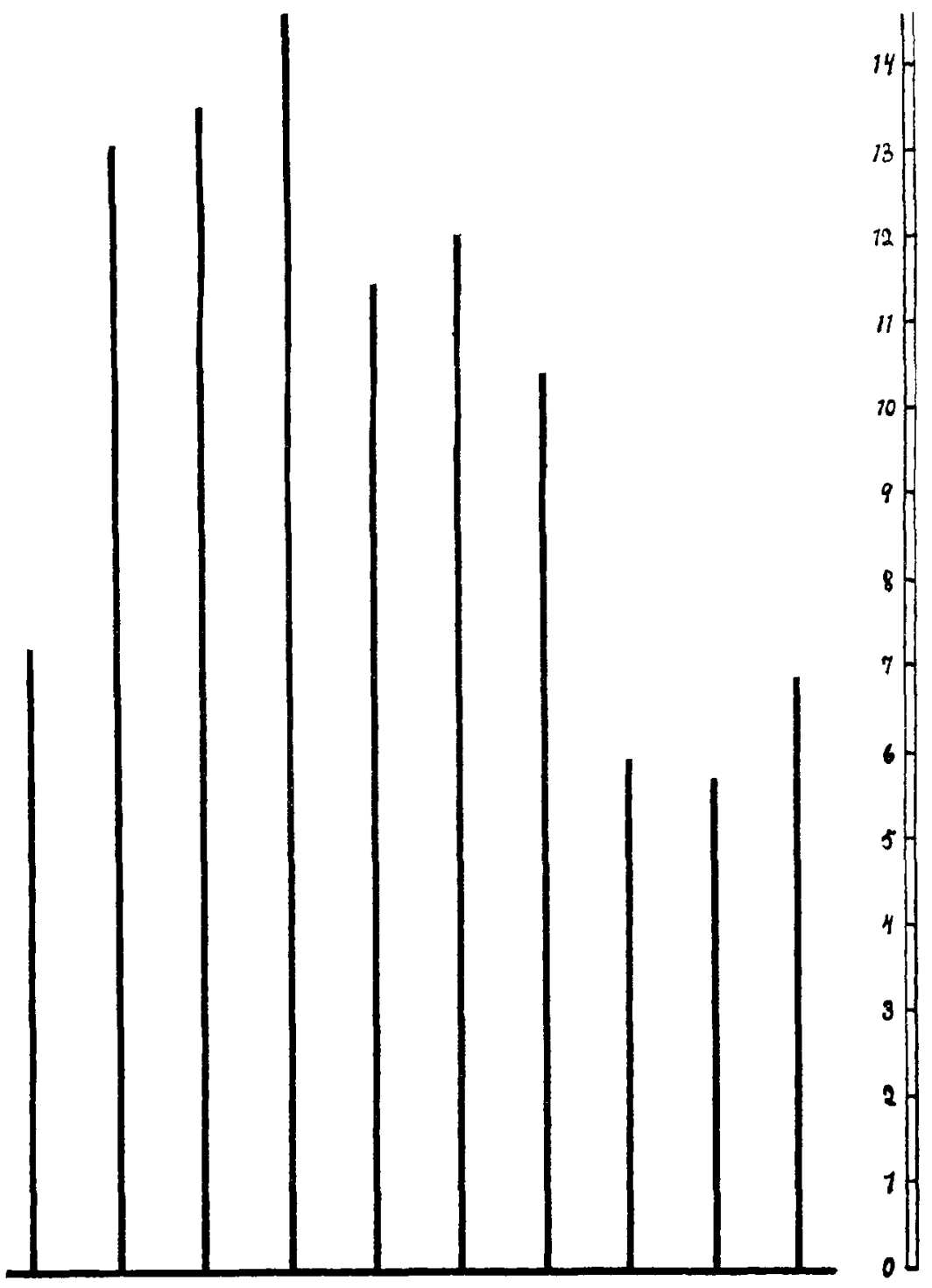

C $\frac{7 m}{8192} \frac{7 m}{16384} \frac{m}{32768} \frac{m}{65536} \frac{m}{131072} \frac{m 4}{262144} \frac{m}{524288} \frac{m}{1048576} \frac{m}{2097152}$

\section{Series 9.}

\section{PLATE 5}

Diagram showing the actual average root growth during I6S hours of corn seedngs in the control $(C)$ and in various concentrations of $\mathrm{MgSO}_{7}$, series 9 .

The inarginal units are in centimeters. 
rate increased in $m / 32768$, remained about the same in $m / 8192$, and continued to fall in the control. It might be concluded that the gradual fall in rate after the first 48 hours was due to the increasing concentration of the solutions from loss of water. This idea is controverted by the fact that seedlings left for several weeks in solutions which are at first slightly toxic, will gradually gain upon the control. This was notably shown in $m$ ro24, series Io, with corn seedlings. At the end of the first week the growth was about the same as the control. The seedlings nere allowed to grow in the same solution for three weeks more, when the growth was nearly double that in the control. The same response has already been noted in pea seedlings grown in magnesium sulphate solution $m S 192$, in which case long secondary roots developed when the seedlings were left in the same solution for several weeks. These results would seem to indicate that the magnesium sulphate was gradually removed from the solution and utilized by the plants. (See table Io).

TABI,E IO

Comparison between daily growth rate in control, $m 8$ Ig2, and $m 32768$ series 9 and 10, corn seedlings and nagnesium sulphate; the fluid having been changed

at the end of 96 hours in series 9 , but not until the 9 th day in series 10. Average growth given in millimeters.

\begin{tabular}{|c|c|c|c|c|c|c|c|c|}
\hline Culture & series. & $\begin{array}{l}\text { st \& 2nd } \\
24 \text { hrs. }\end{array}$ & $\begin{array}{c}3 \text { rd } \\
24 \text { hrs. }\end{array}$ & $\begin{array}{c}\text { 4th \& } 5 \text { th } \\
24 \text { hrs. }\end{array}$ & $\begin{array}{l}\text { 6th \& } 7 \text { th } \\
24 \text { hrs. }\end{array}$ & $\begin{array}{l}8 \mathrm{th} \& \text { gth } \\
24 \mathrm{hrs} .\end{array}$ & $\begin{array}{l}\text { Icth } \\
24 \text { hrs. }\end{array}$ & $\begin{array}{l}\text { Itth \& i } 2 \text { th } \\
24 \mathrm{hrs} .\end{array}$ \\
\hline Control & 9. & $25 \cdot 3$ & 16.5 & I 2.8 & 13.6 & & & \\
\hline Control & 10. & 32. & I5. & 19. & 20.75 & 12. & 3.75 & 2.75 \\
\hline \multicolumn{9}{|l|}{$\mathrm{MgSO}$} \\
\hline$m 8192$ & 9. & 27.3 & 21.6 & 30.6 & $53 \cdot 3$ & & & \\
\hline$m S[92$ & 10. & 40.7 & 20.5 & 20.7 & I5. & 10.5 & 4.75 & 7.25 \\
\hline$m 32768$ & 9. & 24.6 & 21.5 & 37.5 & 58. & & & \\
\hline$m 32768$ & IO. & 46. & 26. & 34.2 & 19.2 & 17. & 8.75 & 21.75 \\
\hline
\end{tabular}

\section{Summary of Conclusions}

Magnesium sulphate in solutions of greater concentrations than m/8192 has a toxic action on most seedlings, the degree of toxicity varying with the type of seedling and with the conditions. An $m / 8192$ solution is toxic to pea seedlings, slightly stimulating to Abutilon, while it has a marked stimulating effect on corn seedlings. Maximum stimulation in magnesium sulphate results in solutions from $m / 32768$ to $m / 131072$, the point again varying according to the kind of seedlings grown. When magnesium sulphate is used in proper dilutions there may be produced a total growth nearly double that in the control ; or in the case of Abutilon seedlings, a growth of the primary root 15 times that in the control. Not only is the growth of the primary root increased, but the lateral roots develop sooner, are more numerous, and attain a greater growth. Furthermore the stimulation is not limited to the root system, but the magnesium forces a more rapid and a greater growth of the hypocotyl 


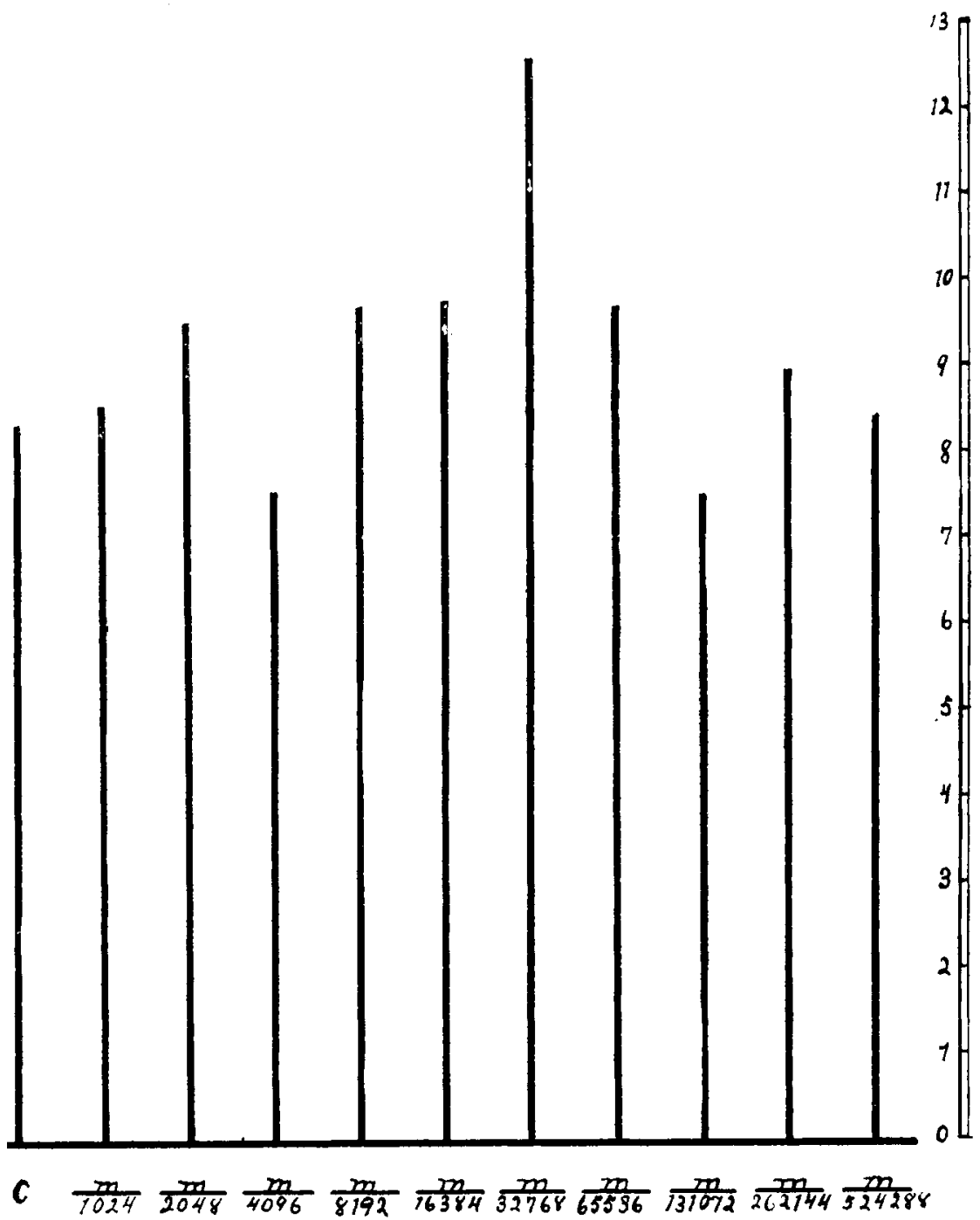

\section{Series 10}

PLATE 6

Diagram showing the actual average root growth during 168 hours, of corn seedlings in the control $(C)$ and in the various concentrations of $\mathrm{MgSO}_{4}$, series Io.

The marginal units are in centimeters.

and plumule. In these same concentrations, calcium nitrate causes very little stimulation. 
In addition to the marked stimulation which magnesium sulphate causes when it is used in dilutions from $m / 16,384$ to $m / 524288$, it increases the vitality of the seedlings. The seedlings grown in the magnesium sulphate outlived those in the control by two or three weeks, and in some cases by a greater period.

From the foregoing results and conclusions, it is then evident that magnesium sulphate, in the absence of other salts, is not necessarily injurious in its effects, but on the other hand may be highly beneficial; while any inhibitory action is due to the presence of a relatively large proportion of magnesium in the solution.

Lastly the writer wishes to acknowledge the assistance of Dr. William J. Gies under whose direction these experiments have been carried on in the laboratories of the New York Botanical Garden.

[CONTRIBLTION FROM THE DIVLSION OF FOODS, BLREAl OF ChEMISTRE, U. S. DEPARTMENT OF AGRICUITLRE].

\title{
STUDIES ON APPLE JUICE.
}

\author{
BY H. C. CrOR :
}

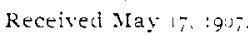

Experimental work on the preparation of unfermented apple juice was carried ont during the past season at the large fruit farm of Mr. Isaac Pollard at Nehawka, Nebraska. The results of this work are given in the Year-Book of the Department of Agriculture for 19o6. Very briefly the method which was developed for the preparation of the juice consisted first in removing the sediment from the juice of the fresh fruit by passing it twice through a milk separator. The juice was then carbonated if desired, canned, or bottled, and finally sterilized by heating for short periods of time at temperatures not exceeding $70^{\circ}$.

()ther lines of work relating to apples were carried on at the same time and as the literature on the chemistry of this important fruit in Anerica is rather meagre, it is believed that the data here presented will be of interest.

Analyses of the following juices were made:

(a) Juices of the cull apples employed for cider making.

(b) Juices from the cider-mill at various times cluring the season.

(c) Juices of standard varieties of apples grown at Nehawka.

(d) Juices of summer apples in regard to their value for vinegar stock.

(e) Juices of decaying apples.

The methods employed were briefy as follows: Solicls were determined by the Brix spindle. This method has been shown by Browne' to be quite accurate for fruit juices. Determination of acid: ten gram samples of juice were diluted with distilled water. heated to boiling, and titrated with tenth normal alkali, using phenol phthalein as indicator. Sugars were

1 This Journal, 23, 875. 